Article

\title{
Study of Alzheimer's Disease-Related Biophysical Kinetics with a Microslit-Embedded Cantilever Sensor in a Liquid Environment
}

\author{
Myung-Sic Chae ${ }^{1,2,+}$, Jinsik Kim ${ }^{3,+}$, Yong Kyoung Yoo ${ }^{4}$, Jeong Hoon Lee ${ }^{4}$, Tae Geun Kim ${ }^{2}$ and \\ Kyo Seon Hwang ${ }^{1, *}$ \\ 1 Department of Clinical Pharmacology and Therapeutics, College of Medicine, Kyung Hee University, \\ Seoul 02447, Korea; bechu88@gmail.com \\ 2 School of Electrical Engineering, Korea University, Seoul 02841, Korea; tgkim1@korea.ac.kr \\ 3 Department of Medical Biotechnology, College of Life Science and Biotechnology, Dongguk University, \\ Seoul 10326, Korea; lookup2@dongguk.edu \\ 4 Department of Electrical Engineering, Kwangwoon University, Seoul 01897, Korea; \\ yongkyoung0108@gmail.com (Y.K.Y.); jhlee@kw.ac.kr (J.H.L.) \\ * Correspondence: k.hwang@khu.ac.kr; Tel.: +82-2-958-2830 \\ + These authors contributed equally to this work.
}

Received: 6 July 2017; Accepted: 5 August 2017; Published: 7 August 2017

\begin{abstract}
A microsized slit-embedded cantilever sensor (slit cantilever) was fabricated and evaluated as a biosensing platform in a liquid environment. In order to minimize the degradation caused by viscous damping, a $300 \times 100 \mu \mathrm{m}^{2}$ (length $\times$ width) sized cantilever was released by a $5 \mu \mathrm{m}$ gap-surrounding and vibrated by an internal piezoelectric-driven self-actuator. Owing to the structure, when the single side of the slit cantilever was exposed to liquid a significant quality factor $(Q=35)$ could be achieved. To assess the sensing performance, the slit cantilever was exploited to study the biophysical kinetics related to $\mathrm{A} \beta$ peptide. First, the quantification of $\mathrm{A} \beta$ peptide with a concentration of $10 \mathrm{pg} / \mathrm{mL}$ to $1 \mu \mathrm{g} / \mathrm{mL}$ was performed. The resonant responses exhibited a dynamic range from $100 \mathrm{pg} / \mathrm{mL}$ to $100 \mathrm{ng} / \mathrm{mL}(-56.5$ to $-774 \Delta \mathrm{Hz})$ and a dissociation constant $\left(\mathrm{K}_{\mathrm{D}}\right)$ of binding affinity was calculated as $1.75 \mathrm{nM}$. Finally, the $\mathrm{A} \beta$ self-aggregation associated with $\mathrm{AD}$ pathogenesis was monitored by adding monomeric $A \beta$ peptides. As the concentration of added analyte increased from $100 \mathrm{ng} / \mathrm{mL}$ to $10 \mu \mathrm{g} / \mathrm{mL}$, both the frequency shift values ( -813 to $-1804 \Delta \mathrm{Hz}$ ) and associate time constant increased. These results showed the excellent sensing performance of the slit cantilever overcoming a major drawback in liquid environments to become a promising diagnostic tool candidate.
\end{abstract}

Keywords: cantilever sensor; biosensor; viscous damping; Alzheimer's disease

\section{Introduction}

The need exists for a rapid and accurate method for early diagnosis of Alzheimer's disease (AD), a severe neurodegenerative disorder. Early diagnosis of AD is critical for its prevention and treatment. To address this need, numerous biological sensing platforms have been proposed for detection of the pathogenic biomarkers of the disease as a target molecule [1,2]. Amyloid- $\beta$ (A $\beta)$ peptides are known to be a representative clinical hallmark of $A D$ and characterize its status [3,4]. Moreover, the structural deformation of $A \beta$ into insoluble plaque forms, such as oligomers and fibrils, is a pathogenic event strongly associated with progression of the disease due to its neurotoxicity, which leads to cell death and neuronal dysfunction. Therefore, detection of $A \beta$ and monitoring its condition as a target molecule can be a crucial strategy for early diagnosis of AD. To achieve this objective for clinical application, the 
biosensors must demonstrate an outstanding sensitivity, selectivity, and robustness, regardless of the working environment.

Over the last two decades, miniaturized cantilever sensors have attracted considerable attention for the development of biological and chemical sensing applications [5-8]. The detection of physical, chemical, and biological interactions on the cantilever surface relies on measuring changes in cantilever bending (static mode) or in the resonating characteristic (dynamic mode).

In particular, the use of dynamic-mode cantilever sensors, one of the major operating methods, is suitable for detection of a small amounts of target molecules by measuring the shift of resonant frequency caused by effective mass loading on the surfaces compared to the static mode which observes the deflection of the beam caused by surface stress [9]. Most dynamic-mode cantilever sensors guarantee excellent behaviors in an air or under vacuum conditions. On the other hand, in a liquid environment, the sensing performance is drastically degraded by the reduction of the quality factor (Q-factor) on account of the viscous damping on the structure. Thus, a number of dynamic cantilever-based biosensors have been reported $[10,11]$ and various technologies have also been proposed to overcome this issue, including a suspended microchannel resonator [12] and use of high-order resonance [13].

Here, we present a piezoelectric-driven microslit cantilever sensor (slit cantilever) for developing a biological application to diagnose $\mathrm{AD}$ in a liquid environment. The fabricated slit cantilever was resonated by an embedded PZT self-actuator to avoid the need for additional actuating modules. The resonant frequency the sensor was measured by a laser Doppler vibrometer (LDV). Only 2 3\% error was shown in the air. The $5 \mu \mathrm{m}$ gap of the slit surrounding the cantilever enabled a single side of the surface to be exposed when the liquid was introduced due to its meniscus. The Q-factor of the slit cantilever in liquid on the top surface showed a better value $(Q=35)$ in the case of filling both surfaces. It was sufficient to enable a high resolution in a liquid environment (Figure 1).
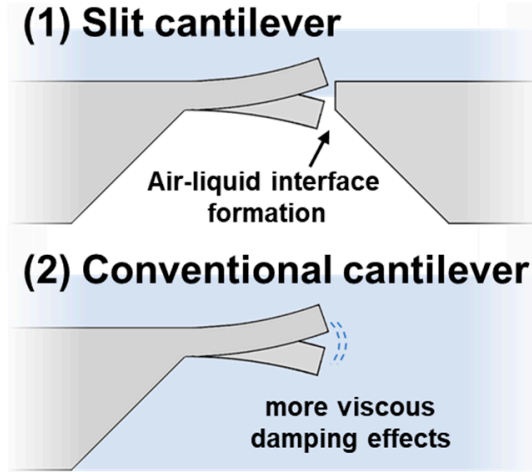

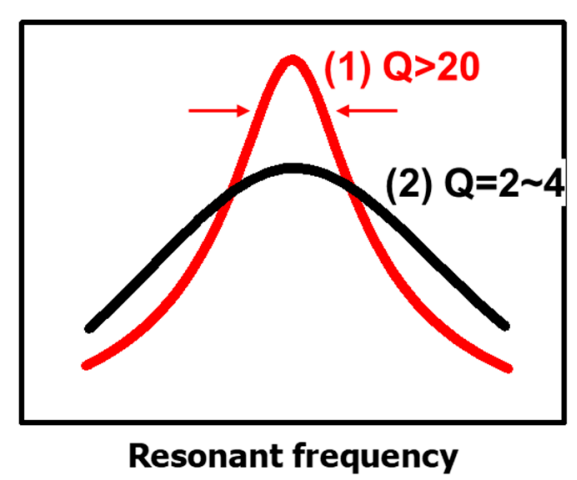

Figure 1. Schematic illustration of slit cantilever compared to the conventional structure of cantilever sensors in liquid environment and a conceptual diagram showing an enhanced quality-factor of the slit cantilever by reducing viscous damping due to formation of the air-liquid interface.

To assess the slit cantilever as a biological sensing tool, the quantification and monitoring of the $A \beta$ peptide self-aggregation process were studied using kinetic analysis. As noted above, a condition with a trace of $A \beta$ is critical to the clinical diagnosis and pathological study of $A D$. Firstly, the quantitative detection of $A \beta$ peptide with a concentration of $10 \mathrm{pg} / \mathrm{mL}$ to $1 \mu \mathrm{g} / \mathrm{mL}$ was performed. For the specific binding interactions of analytes, the specific-binding monoclonal antibody was chemically immobilized on the cantilever surface. The frequency change due to direct mass loading on the surface could be measured by the $A \beta$ and antibody interaction. Furthermore, the dissociation constant $\left(K_{D}\right)$ of the $A \beta-m A b$ binding affinity was calculated by fitting the quantification result to the thermodynamic isotherm. By using the slit cantilever to monitor the self-aggregation of monomeric $A \beta$ peptide on the $A \beta$ oligomeric intermediate, which was immobilized on the surface, the time-dependent responses 
caused by $A \beta$ aggregation were investigated with different analyte concentrations. The self-growth of $A \beta$ peptides on the functionalized surfaces was visually confirmed through topographic analysis.

\section{Materials and Methods}

\subsection{Sensor Fabrication}

The microslit cantilever sensors were fabricated based on the fabrication processes used in previous studies [14,15]. However, as shown in Figure 2a, two major points were considered for a desirable operation in liquid: (1) the cantilever beam was released by a $5 \mu \mathrm{m}$ gap of the slit to decrease viscous damping; (2) piezoelectric material, PZT, was removed from the cantilever structure and indirectly worked as an internal actuator. Details of the fabrication process and an optical image of the fabricated device are depicted in Figure $2 b-g$. First, a 4-inch multilayered $\mathrm{SiN}_{\mathrm{x}} / \mathrm{Si} / \mathrm{SiN}_{\mathrm{x}} / \mathrm{Ta} / \mathrm{Pt}$ substrate was prepared. A low-stress $\operatorname{SiN}_{\mathrm{x}}$ thin film with a thickness of $1 \mu \mathrm{m}$ was deposited on both sides of the Si wafer by low-pressure chemical vapor deposition. This formed the main structure. Next Ta and Pt thin films with respective thicknesses of $30 \mathrm{~nm}$ and $150 \mathrm{~nm}$ were deposited on the $\mathrm{SiN}_{\mathrm{x}}$ followed by deposition of a PZT thin film with $2 \mu \mathrm{m}$ thickness.
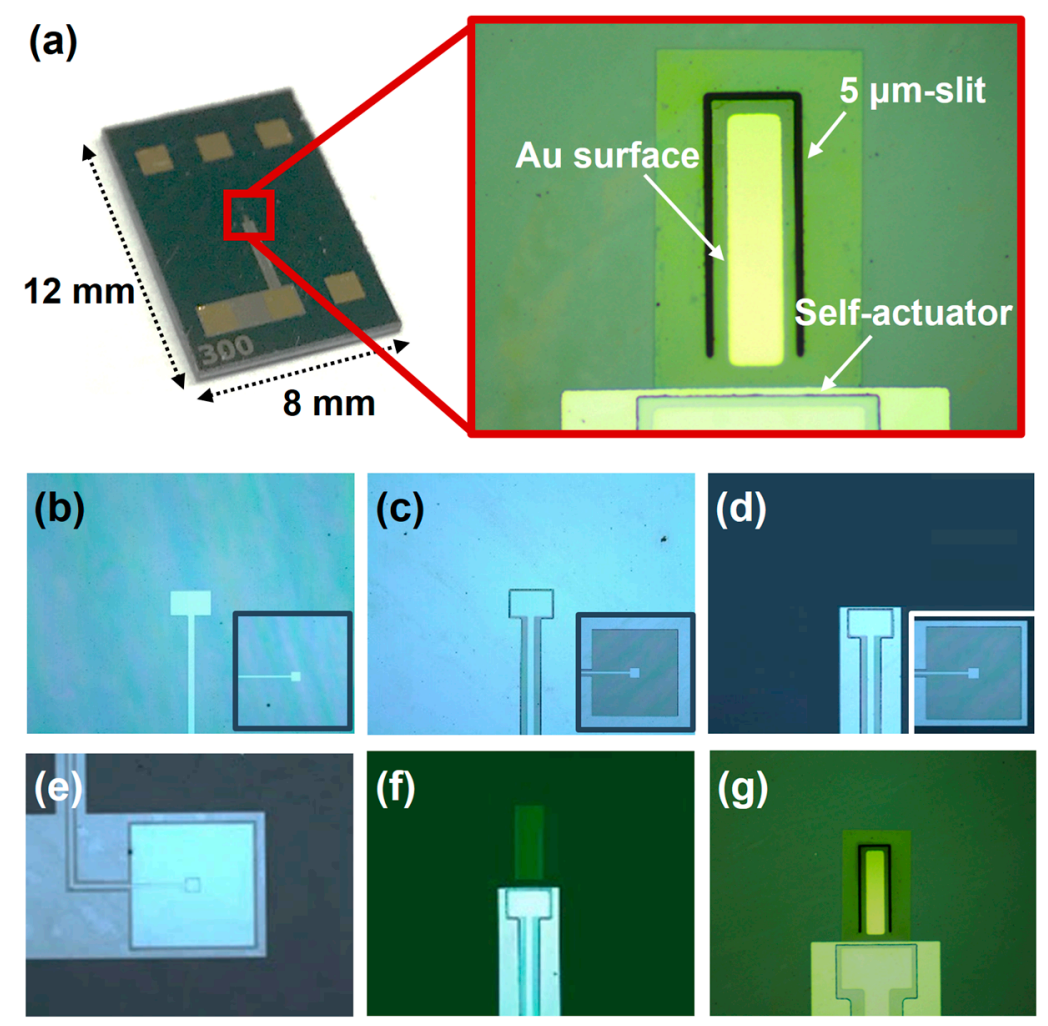

Figure 2. Optical images of the slit cantilever and fabrication process (a) a single die of the slit cantilever sensor and fabrication details for (b) upper Pt etching; (c) PZT wet-etching; (d) bottom Pt etching; (e) Au contact pad formation; (f) backside-Si bulk etching; and (g) biological active layer formation and cantilever releasing.

The PZT thin film was synthesized and deposited by a sol-gel method on Ta/Pt substrate. Then, the upper Pt thin film with a thickness of $100 \mathrm{~nm}$ was deposited on the PZT film by RF sputtering to form a Pt/PZT/Pt capacitance structure to function as a piezoelectric self-actuator. After the formation of multilayers on a 4-inch Si substrate, the top Pt, PZT, and bottom Ta/Pt layer were etched by an inductive coupled plasma (ICP) etching process (Figure 2a-c). 
Then, a $200 \mathrm{SiO}_{2}$ thin film was deposited and etched to function as a passivation layer, and $\mathrm{Cr} / \mathrm{Au}$ patterns of $50 / 200 \mathrm{~nm}$ for contact pads were formed by a lift-off technique (Figure $2 \mathrm{~d}$ ). The Si was wet-etched with $30 \%$ potassium hydroxide $(\mathrm{KOH})$ solution from the backside of the substrate (Figure 2e). Finally, the formation of a 10/50 nm-thick $\mathrm{Cr} / \mathrm{Au}$ patterns as a functional area of biological interactions by a lift-off technique was followed by the releasing of the cantilever patterns by $5 \mu \mathrm{m}$ gap surroundings (Figure 2g). As shown in the figure, the single cantilever has dimensions of $100 \times 300 \mu \mathrm{m}^{2}$ and a thickness of $1.25 \mu \mathrm{m}$.

\subsection{Surface Functionalization}

To detect the target molecules, a commercial monoclonal $6 \mathrm{E} 10$ antibody (mAb, $10 \mu \mathrm{g} / \mathrm{mL}$, Covance, Princeton, NJ, USA) was immobilized on the cantilever surfaces by using a conventional coupling method. The $\mathrm{mAb}$ is known to include a specific binding ligand with the first 1-16 sequence of human $\mathrm{A} \beta$ peptides [16,17]. Prior to antibody immobilization, the slit cantilever with a $50 \mathrm{~nm}$ thick Au surface was cleaned with piranha solution (a 4:1 ratio of $\mathrm{H}_{2} \mathrm{SO}_{4}$ to $\mathrm{H}_{2} \mathrm{O}_{2}$ ) and rinsed with deionized water (DI). In addition, $10 \mathrm{mM}$ of 11-Mercaptoundecanoic acid (11-MUC, Sigma-Aldrich, St. Louis, MO, USA) diluted in ethanol was treated for $12 \mathrm{~h}$ on the Au surface of the sensor to establish a self-assembled monolayer. The MUC-modified slit cantilever was immersed in a mixture of 1-ethyl-3-(3-dimethylaminopropyl) carbodiimide (EDC, $80 \mathrm{mM}$, Sigma-Aldrich) and N-hydroxysuccinimide (NHS, $20 \mathrm{mM}$, Sigma-Aldrich) dissolved for $2 \mathrm{~h}$ in $10 \mathrm{mM}$ of phosphate-buffered solution (PBS, $\mathrm{pH}=7.4$ ). Then, $\mathrm{mAb}$, which was diluted as $10 \mu \mathrm{g} / \mathrm{mL}$ in $10 \mathrm{mM}$ PBS, was immobilized on the functionalized surface of the slit cantilever for $2 \mathrm{~h}$, followed by rinsing with PBS and DI.

\subsection{Preparation of Oligomeric Intermediates}

The synthetic $A \beta_{42}$ peptide (Sigma-Aldrich) was dissolved in dimethyl sulfoxide (DMSO) and diluted to a final concentration of $10 \mathrm{mg} / \mathrm{mL}$ in PBS solution. The solution was incubated without agitation at $37^{\circ} \mathrm{C}$ for $48 \mathrm{~h}$ to form heterogeneous oligomeric intermediates [18-20]. The molecule acts as a seed for self-growth of $A \beta$ peptides on the sensor surface. For monitoring the $A \beta$ aggregation, the prepared oligomeric intermediates were immobilized on the cantilever surface. The slit sensor surface was activated with 11-MUC, followed by EDC-NHS coupling, which was the same as the mAb immobilization process. The functionalized slit cantilever was immersed in the prepared seed solution for $24 \mathrm{~h}$. After rinsing with PBS, the sensor was treated with ethylenediamine (EDA, Sigma-Aldrich) to avoid nonspecific binding.

\section{Results and Discussion}

\subsection{Resonant Frequency Characterization of the Slit Cantilever}

To measure the resonant frequency of the slit cantilevers, the optical setup was established as depicted in Figure 3a. An external 3.0 V peak-to-peak voltage sinusoidal wave was induced at the top electrodes with $1.5 \mathrm{~V}$ of superimposed direct current (DC) voltage to vibrate the Pt-PZT-Pt capacitance and thereby enable measurement of the fundamental resonant frequency. Similar to most resonators, the slit cantilever has multiple vibrating modes. In this study, we measured the three dominant modes of resonant frequency within $500 \mathrm{kHz}$. As shown in Figure $3 \mathrm{~b}$ (black line), the resonant frequencies of first to third modes were measured as $15.872 \mathrm{kHz}, 103.165 \mathrm{kHz}$, and $289.426 \mathrm{kHz}$. According to Equation (1), the theoretical nth undamped resonant frequency of the cantilever in air $\left(f_{n, a i r}\right)$ can be calculated:

$$
f_{n, a i r}=\frac{\lambda_{n}^{2}}{2 \pi} \sqrt{\frac{E I}{m^{*} L^{4}}}
$$


where $\lambda_{n}$ is the eigenvalue of the $n$th vibrating mode, $m^{*}$ represents the distributed mass per unit length, $L$ is the length of the cantilever beam, $E$ denotes Young's modulus, and $I$ is the moment of inertia of the cross section.

\section{(a) LASER}

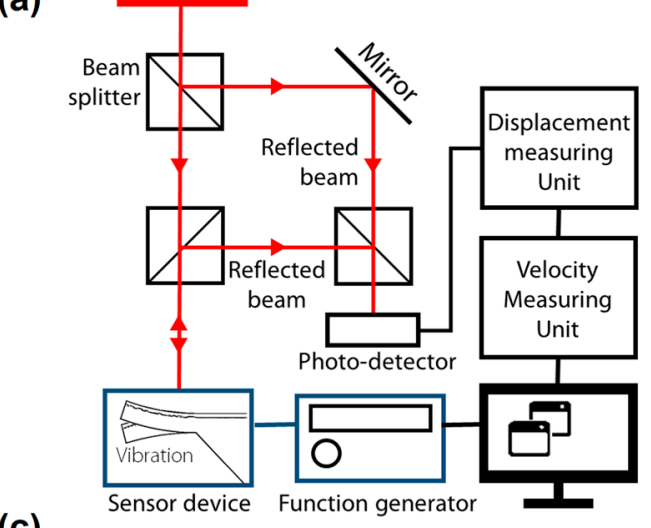

(c)

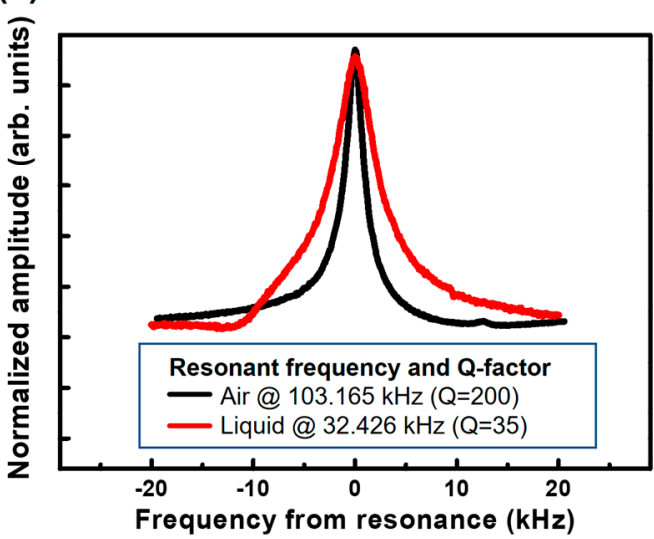

(b)

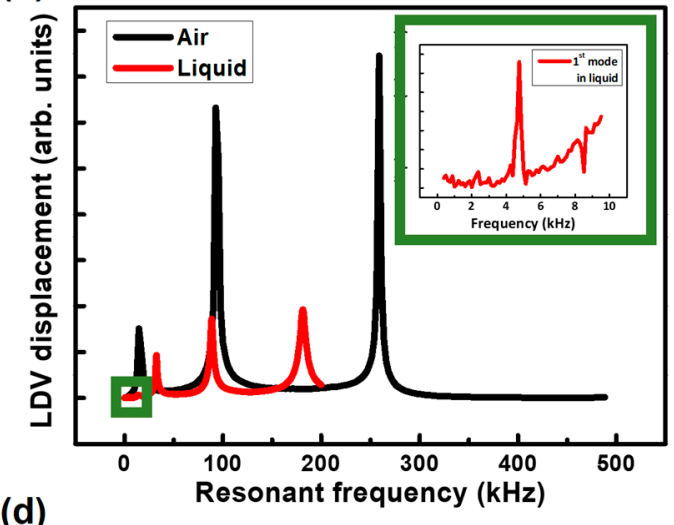

(d)

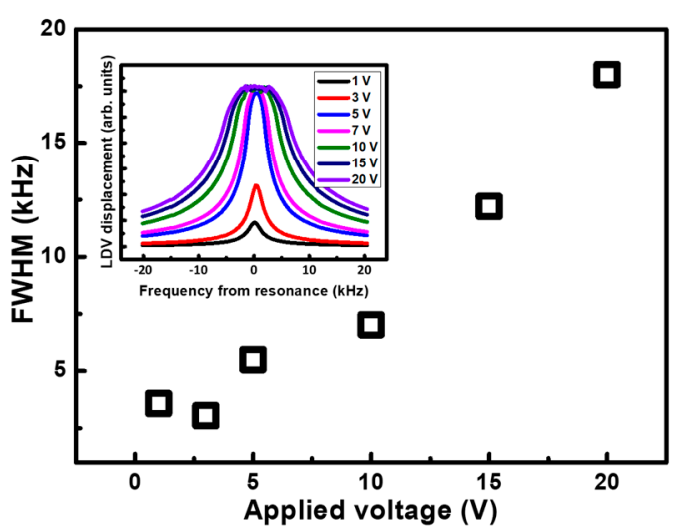

Figure 3. Characterization of resonating slit cantilever in air and liquid conditions. (a) An optical measurement setup of the slit cantilever sensor; (b) Measurement of first $\sim$ third mode resonant frequencies in air and distilled water; (c) Direct comparison of an identical mode resonance peak between air and liquid phases; (d) Optimization of an induced voltage toward the PZT self-actuating layer.

Compared to theoretical values of vibrating modes, which were calculated by Equation (1), the difference was $2.1 \%, 1.5 \%$, and $1.7 \%$ for first to third modes, respectively, and the wafer-level distribution was less than 5\% (Table S1). The high similarity between the actual and theoretical values in the air condition indicates that our devices were well-fabricated, as intended. To inject the solution on the single surface of the sensor, the slit cantilevers were covered with a polydimethylsiloxane (PDMS) liquid cell, including a $500 \mu \mathrm{m}$ width-straight microchannel with an inlet and outlet. It was assembled with a loading jig (Figure S1).

As shown in Figure $3 \mathrm{~b}$ (red line), the resonant frequency of all three modes measure at $4.7576 \mathrm{kHz}$, $32.426 \mathrm{kHz}$, and $88.266 \mathrm{kHz}$ for first, second, and third modes, respectively, which decrease to nearly $30 \%$ of the initial values in air on account of the additional mass and viscosity of the filled solution. Although the $\mathrm{Q}$-factor is also decreased, the second and third mode resonances show $\mathrm{Q}=35$ and $\mathrm{Q}=21$ have sufficiently high values to operate in a liquid environment as a sensing platform (Table 1). 
Table 1. First $\sim$ third resonance modes of resonant frequency in air and liquid environments.

\begin{tabular}{ccccc}
\hline \multirow{2}{*}{ Resonance Mode } & \multicolumn{2}{c}{ Air } & \multicolumn{2}{c}{ Liquid } \\
\cline { 2 - 5 } & Resonant Frequency & Q-Factor & Resonant Frequency & Q-Factor \\
\hline 1st & $14.865 \mathrm{kHz}$ & 30 & $4.757 \mathrm{kHz}$ & - \\
2nd & $92.773 \mathrm{kHz}$ & 251 & $32.426 \mathrm{kHz}$ & 35 \\
3rd & $358.789 \mathrm{kHz}$ & 170 & $88.266 \mathrm{kHz}$ & 21 \\
\hline
\end{tabular}

According to a previous study [21], a fundamental resonant frequency in viscous environment can be calculated by Equation (2):

$$
f_{0, l i q}=\frac{1}{2 \pi} \sqrt{\frac{k_{0}+k_{\gamma}}{m_{0}}}
$$

where $f_{0, l i q}$ is the dominant resonant frequency of the slit cantilever in a viscous environment, $k_{0}$ denotes the spring constant of the cantilever, $k_{\gamma}$ represents the spring constant of the surface tension at the air-liquid interface, and $m_{0}$ is the mass of the cantilever beam.

Following Equation (2), the resonant frequency of the slit cantilever in the PBS solution was calculated $34.56 \mathrm{kHz}$, which indicated the second vibration mode of the slit cantilever. Figure $3 \mathrm{c}$ shows a direct comparison of a second mode resonance behavior of the slit cantilever, which has the highest Q-factor in both air and liquid environments. Finally, the operating stability of the slit cantilever was optimized with various conditions of the induced voltage to the PZT actuating layer. As shown in the inset of Figure 3d, the LDV displacements are increased and saturated when a higher voltage is induced. When more than $5 \mathrm{~V}$ is applied, however, the full width at half maximum value of the resonant frequency was increased by broadening the signals. Thus, the PZT self-actuator operating with $3 \mathrm{~V}$ has a stable resonance peak with the sharpest shape.

\subsection{Quantitative Detection of A $\beta$ Peptide}

To evaluate the sensing performance of the slit cantilever in a liquid environment, quantification of the synthetic $A \beta_{42}$ peptide, which has an identical sequence of 42-residue amino acids associated with human AD, was investigated in a physiological-level concentration. Prior to conducting biomolecular interactions, a drift of resonant frequency was verified and stabilized until steady state (Figure S2). The resonance responses reached its steady state within $200 \mathrm{~min}$ and the frequency maintained for $60 \mathrm{~min}$ with fluctuations up to $4 \mathrm{~Hz}$ which can be regarded as a noise level. Detection of target molecules with the slit cantilever is based on the capturing by immobilized mAb on the cantilever beam. It occurs in the measurement of the frequency shift due to mass loading on the surface. Firstly, the specific antibody $(\mathrm{mAb})$ of $10 \mu \mathrm{g} / \mathrm{mL}$ was chemically immobilized on the $60 \mu \mathrm{m} \times 280 \mu \mathrm{m}$ dimension of the Au surface ( $50 \mathrm{~nm}$ thickness) of the slit cantilever. The $\mathrm{A} \beta_{42}$ peptide was diluted with a ten-fold difference from $10 \mathrm{pg} / \mathrm{mL}$ to $1 \mu \mathrm{g} / \mathrm{mL}$ in $10 \mathrm{mM}$ PBS. The prepared $\mathrm{A} \beta_{42}$ solution was individually introduced into the slit cantilever for $30 \mathrm{~min}$, followed by rinsing with PBS. The changes of resonant frequencies in PBS were measured before and after the recognition interactions between $\mathrm{mAb}$ and target analytes. The resonant frequency decreased according to the concentration increment of target analytes owing to mass adsorption of $A \beta_{42}$ to the specific binding site of the immobilized $\mathrm{mAb}$. The average values of the frequency shifts were measured as $-15.5,-56.5,-119.5,-472.5,-774$ and $-799 \mathrm{~Hz}$ for the concentrations from $10 \mathrm{pg} / \mathrm{mL}$ to $1 \mu \mathrm{g} / \mathrm{mL}$, respectively. As noted earlier, these responses were satisfied with at least three-sigma significance in terms of the signal-to-noise ratio of the sensors.

As shown in Figure 4a, a typical S-shape relationship of specific recognition reactions is shown with the saturated responses in the high concentration range $A \beta(\sim 1 \mu \mathrm{g} / \mathrm{mL})$, which implies that the $\mathrm{mAb}$ binding sites are fully occupied by $\mathrm{A} \beta$ peptides. Compared to small frequency changes at the lowest level of analytes, an increment trend between the frequency shift in the range of $100 \mathrm{pg} / \mathrm{mL}$ to 
$100 \mathrm{ng} / \mathrm{mL}$ shows that the $\mathrm{A} \beta_{42}$ logarithmic concentration can be regarded as a dynamic range of the sensor with a sensitivity of $330 \mathrm{~Hz} /$ decade.
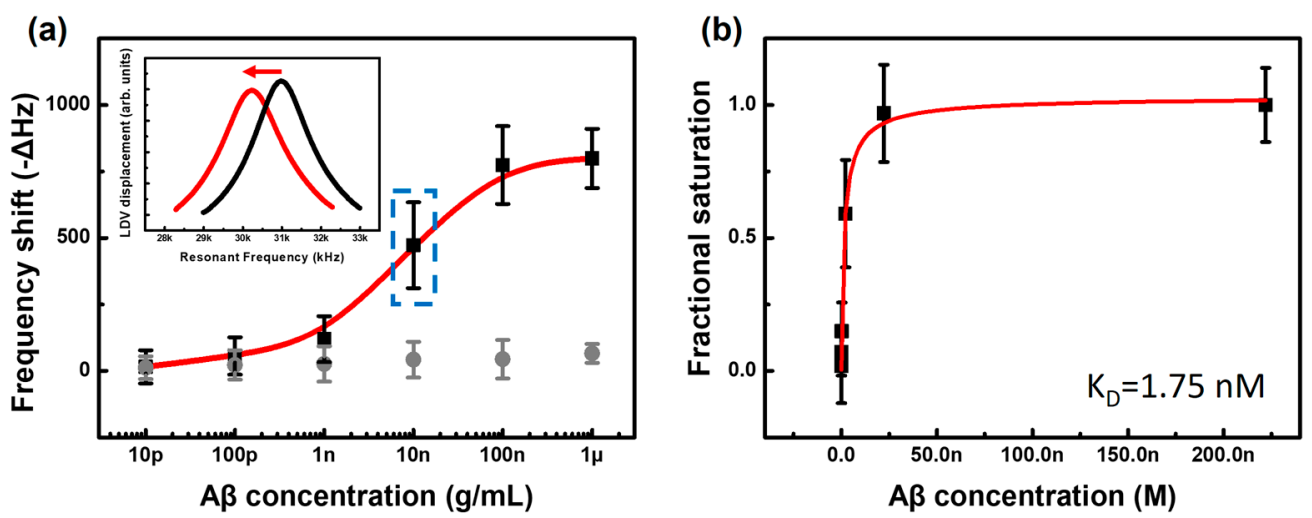

Figure 4. Quantification of $A \beta_{42}$ peptide as a target analyte using the slit cantilever. (a) Responses of resonant frequency vs. logarithmic concentration of analytes (black square) and negative control with PSA protein (grey circle); (b) Estimation of the dissociation constant of specific recognition by fitting the thermodynamic isotherm model.

Based on the cerebrospinal fluid (CSF) levels of A $\beta$ peptides in recent studies [22-25], the dynamic range of the slit cantilever suggested in the experimental results is highly effective when the AD subjects and normal subjects are distinguished. Moreover, when prostate cancer antigen (PSA) protein were introduced as a control experiment, no obvious responses were observed, as shown in Figure 4a (grey circle).

The result of the $A \beta_{42}$ quantification with the slit cantilever is plotted in the figure according to the relation between the fractional saturation of $\mathrm{mAb}$ and the concentration of target molecules on $\mathrm{a}$ linear scale (Figure $4 \mathrm{~b}$ ). The fractional value of saturation, which is an essential quantity for examining a binding affinity, is defined as the number of occupied binding sites on the mAb-immobilized surface divided by the total number of binding sites. We assumed the frequency response of $1 \mu \mathrm{g} / \mathrm{mL}$ reflects that the surface was fully saturated by the analytes to calculate the proportion. Using this approach, the equilibrium dissociation constant $\left(\mathrm{K}_{\mathrm{D}}\right)$ between the $\mathrm{mAb}$ and $\mathrm{A} \beta_{42}$ interactions could be calculated. Determining $K_{D}$ is important for evaluating the relevance and standard protein analysis of the biosensors associated with the binding interactions between biological molecules, such as an antibody-antigen affinity or protein adsorption.

To obtain the above value, the simplest model of the 1:1 binding kinetic between target analytes (A) and $\mathrm{mAb}(\mathrm{B})$ was applied, as shown in Equation (3):

$$
[\mathrm{A}]+[\mathrm{B}] \underset{k_{\text {off }}}{\stackrel{k_{\text {on }}}{\leftrightarrows}}[\mathrm{AB}]
$$

where $k_{o n}$ is an association rate, and $k_{\text {off }}$ denotes the dissociation rate having different units: $\left[\mathrm{M}^{-1} \cdot \mathrm{s}^{-1}\right]$ and $\left[\mathrm{s}^{-1}\right]$. In the very simplest type of 1:1 binding affinity of $A \beta_{42}(\mathrm{~A})$ and $\mathrm{mAb}(\mathrm{B})$ to form a complex $(\mathrm{AB}), \mathrm{K}_{\mathrm{D}}$ is expressed as:

$$
K_{D}=\frac{k_{o f f}}{k_{o n}}=\frac{[\mathrm{A}][\mathrm{B}]}{[\mathrm{AB}]}
$$

According to Equation (4), the definition of $K_{D}$ is manipulated to acquire the following equation:

$$
\frac{[\mathrm{AB}]}{[\mathrm{B}]}=\frac{[\mathrm{A}]}{K_{D}+[\mathrm{A}]}
$$


Meanwhile, Equation (5) predicts the hyperbolic plot of fractional saturation ([AB]/[B]) vs. $A \beta$ concentration. This curve follows isotherms for relatively obscure thermodynamic reasons. Moreover, Equation (5) shows that the $\mathrm{K}_{\mathrm{D}}$ value is defined as [A], where the fractional saturation meets 0.5. As shown in Figure $4 \mathrm{~b}$, the $\mathrm{K}_{\mathrm{D}}$ value of $1.75 \mathrm{nM}$ is obtained by a global fit of the Langmuir isotherm $\left(\chi^{2}=0.010958\right)$, which was developed to describe the adsorption of molecules on a solid surface [26]. The acquired value is consistent with those of previous studies $(1.2 \mathrm{nM})$ using conventional surface Plasmon resonance (SPR) [27]. The slit cantilever result demonstrates the validity of the specific recognition of $A \beta$ peptides. It can thus be used as an analytic tool for biological kinetics.

\subsection{Monitoring Time-Dependent Responses of A $\beta$ Aggregation}

The aggregation process of $\mathrm{A} \beta$ peptides on the cantilever surface was monitored by immobilization of oligomeric seeds on the cantilever surfaces. In terms of AD clinical research, it is important to quantitatively understand the self-assembly of the $A \beta$ aggregates because neurotoxicity occurs during the growth process [28,29]. Compared to traditional methods for $A \beta$ aggregation analysis, such as fluorescent assay or SPR, the $A \beta$ growth rate can be measured within minutes and achieved in comparable concentrations of detection limits with the slit cantilever owing to its high sensitivity and direct quantification of bound analytes on the surface in solution $[30,31]$. Furthermore, in terms of detection techniques using a cantilever sensor, this approach using oligomeric seeds could be developed as a platform for the study of diseases-related biophysics following previous studies such as nanoparticles [32] or a single-stranded DNA probe [33].

To lead $A \beta$ growth, a heterogeneous oligomeric intermediate was prepared as the $A \beta$ growth seed, and it was immobilized on the cantilever surface. Then, a monomeric $A \beta_{42}$ solution with concentrations of $100 \mathrm{ng} / \mathrm{mL}(22.2 \mathrm{nM}), 1 \mu \mathrm{g} / \mathrm{mL}(222 \mathrm{nM})$, and $10 \mu \mathrm{g} / \mathrm{mL}(2.22 \mu \mathrm{M})$ was injected into the sensor. The immobilized $A \beta$ intermediates could be grown by the binding interactions of added $A \beta$ peptides to form elongated aggregates [20,34]. The time-dependent responses of the resonant frequencies, which relied on quantitative amyloid growth on the sensor surface, were obtained as shown in Figure 5a. The results show the different growth rates and frequency shifts depending on the concentration of added $A \beta_{42}$ peptide.
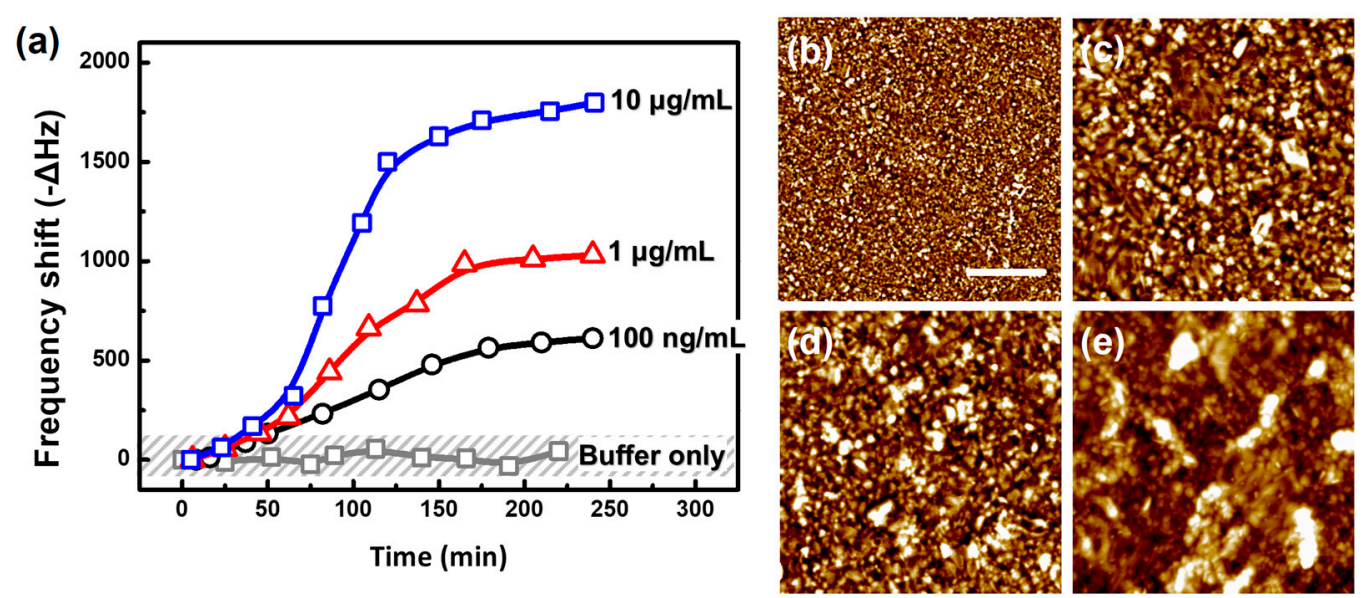

Figure 5. The resonant responses and topographic analysis of $A \beta$ aggregation on sensor surfaces (a) Monitoring time-dependent responses of $\mathrm{A} \beta$ aggregation on the seed-immobilized cantilever surface with newly added $\mathrm{A} \beta_{42}$ peptide with concentrations of $100 \mathrm{ng} / \mathrm{mL}, 1 \mu \mathrm{g} / \mathrm{mL}$, and $10 \mu \mathrm{g} / \mathrm{mL}$; Topographic images of $(\mathbf{b})$ the seed-immobilized Au surface and $A \beta$ aggregation with concentration of (c) $100 \mathrm{ng} / \mathrm{mL}$; (d) $1 \mu \mathrm{g} / \mathrm{mL}$; and (e) $10 \mu \mathrm{g} / \mathrm{mL}$. (A scale bar is $250 \mathrm{~nm}$ ).

When $A \beta$ aggregation occurs, insoluble plaque forms accumulate. Therefore, several studies have reported the reaction following conventional binding kinetics [35-37]. We assumed the reaction on the 
slit cantilever followed an isotherm and fitted Langmuir isotherm to address the growth process. The association time constant was calculated as $0.007968 \mathrm{~min}^{-1}$ (125.5 $\left.\mathrm{min}\right), 0.01010 \mathrm{~min}^{-1}$ (99.00 $\left.\mathrm{min}\right)$, and $0.01130 \mathrm{~min}^{-1}(88.50 \mathrm{~min})$ for the respective $\mathrm{A} \beta_{42}$ concentrations of $100 \mathrm{ng} / \mathrm{mL}, 1 \mu \mathrm{g} / \mathrm{mL}$, and $10 \mu \mathrm{g} / \mathrm{mL}$. Furthermore, the convergent values of the frequency changes at the saturated growth condition were estimated by fitting the isotherm as $813.0 \mathrm{~Hz}(100 \mathrm{ng} / \mathrm{mL}), 1132 \mathrm{~Hz}(1 \mu \mathrm{g} / \mathrm{mL})$, and $1804 \mathrm{~Hz}(10 \mu \mathrm{g} / \mathrm{mL})$ (Figure S3).

$A \beta$ growth under identical circumstances was verified by topographic analysis using AFM. Figure $5 b$ to e show the topologic images of $A u$ surfaces with an $A \beta$ aggregation reaction under different conditions. The sample surface roughness was $0.7341 \mathrm{~nm}, 1.413 \mathrm{~nm}, 2.224 \mathrm{~nm}$, and $4.694 \mathrm{~nm}$ for the seed-only surface, and $100 \mathrm{ng} / \mathrm{mL}, 1 \mu \mathrm{g} / \mathrm{mL}$, and $10 \mu \mathrm{g} / \mathrm{mL}$ for the monomeric $\mathrm{A} \beta$ peptide-added surface. When the oligomeric seeds were solely immobilized on the surface (Figure $5 b$ ), sub-nm-sized particles were distributed. However, oligomeric structures with length of tens of nanometers were observed when the monomeric $A \beta_{42}$ peptide were introduced (Figure $5 c, d$ ). In particular, a significant size ( $>100 \mathrm{~nm}$ length) of aggregates was confirmed by AFM analysis with a concentration of $10 \mu \mathrm{g} / \mathrm{mL} \mathrm{A} \beta_{42}$ peptide (Figure 5e).

With these results, the $A \beta$ aggregation process supported by prepared oligomeric seeds strongly relates to the initial concentration of newly added monomeric $A \beta$ peptides. Thus, the proposed approach using the slit cantilever can have an important clinical application in AD diagnosis.

\section{Conclusions}

In this study, a cantilever sensor surrounded with a microslit structure was fabricated and its feasibility as a biosensing platform for AD diagnosis was evaluated. Firstly, the resonating characteristic of the slit cantilever was confirmed by measuring the resonant frequency, which was consistent with a theoretical calculation in both air and liquid conditions. In particular, the slit cantilever showed a better $\mathrm{Q}$-factor $(\mathrm{Q}=35)$ in the liquid phase than those of conventional cantilever sensors $(\mathrm{Q}=2 \sim 4)$ since the single side of the sensor surface was in contact with the filled solution by the meniscus. Such properties of the slit cantilever enable study of the AD-related biophysical interactions in the liquid phase. A quantitative detection of $\mathrm{A} \beta_{42}$ peptides was conducted within the concentration of $100 \mathrm{pg} / \mathrm{mL}$ to $10 \mathrm{ng} / \mathrm{mL}$. The results addressed both the valid dynamic range of an AD diagnosis and a dissociation constant $\left(\mathrm{K}_{\mathrm{D}}=1.75 \mathrm{nM}\right)$ of the binding affinity between the specific $\mathrm{mAb}$ and the analytes.

In addition, $A \beta$ aggregation, a crucial pathogenesis in $A D$ progression, was monitored with a different concentration of monomeric $\mathrm{A} \beta$ peptides added into the functionalized sensor surface. The time-dependent responses of resonant frequency indicated that an effective mass loading and a self-assembly growth rate on the sensor surface relied on an initial concentration of added $A \beta$ peptides. The $A \beta$ aggregation on the seed-immobilized surface was verified by a surface roughness comparison using topographic analysis. The results indicated that the proposed slit cantilever operated with an excellent sensing performance and overcame the major drawbacks of existing cantilever sensors in liquid. It is thus a promising technology for use in the clinical diagnosis of AD.

Supplementary Materials: The following are available online at http:/ /www.mdpi.com/1424-8220/17/8/1819/ s1. Figure S1: Preparation of slit the cantilever for measuring the resonant frequency in a liquid environment with (a) a PDMS liquid cell and (b) assembly of a loading jig. Figure S2: Measuring resonant frequency shifts of slit cantilever in the liquid environment showing a drift effect with exposed time until steady state. Figure S3: Fitting the time-dependent responses to the thermodynamic isotherm in case of added $\mathrm{A} \beta_{42}$ concentration of (a) $100 \mathrm{ng} / \mathrm{mL}$, (b) $1 \mu \mathrm{g} / \mathrm{mL}$, and (c) $10 \mu \mathrm{g} / \mathrm{mL}$ added on slit cantilever. Table S1: Comparison of theoretical and actual values of first $\sim$ third mode resonant frequency of slit cantilever.

Acknowledgments: The authors are grateful for financial support from National Research Foundation of Korea (NRF, NRF-2017M3A9E2058046) and the Korea Health Industry Development Institute (KHIDI, Grant No. HI14C3319).

Author Contributions: M.-S.C, J.K. and K.S.H. conceived and designed the experiments; M.-S.C, J.K. and Y.K.Y. performed the experiments; M.-S.C, J.H.L. and K.S.H. analyzed the data; T.G.K. and K.S.H. contributed reagents and materials for the study; M.-S.C. wrote the original draft and J.H.L, T.G.K. and K.S.H. reviewed and edited the manuscript. 
Conflicts of Interest: The authors declare no conflict of interest.

\section{References}

1. Ganesh, H.V.S.; Chow, A.M.; Kerman, K. Recent advances in biosensors for neurodegenerative disease detection. Trends Analyt. Chem. 2016, 79, 363-370. [CrossRef]

2. Kaushik, A.; Jayant, R.D.; Tiwari, S.; Vashist, A.; Nair, M. Nano-biosensors to detect beta-amyloid for Alzheimer's disease management. Biosens. Bioelectron. 2016, 80, 273-287. [CrossRef] [PubMed]

3. Palop, J.J.; Mucke, L. Amyloid- $\beta$-induced neuronal dysfunction in Alzheimer's disease: From synapses toward neural networks. Nat. Neurosci. 2010, 13, 812-818. [CrossRef] [PubMed]

4. Murphy, M.P.; LeVine, H., III. Alzheimer's Disease and the Amyloid- $\beta$ Peptide. J. Alzheimers Dis. 2010, 19, 311-323. [CrossRef] [PubMed]

5. Li, M.; Tang, H.X.; Roukes, M.L. Ultra-sensitive NEMS-based cantilevers for sensing, scanned probe and very high-frequency applications. Nat. Nanotech. 2007, 2, 114-120. [CrossRef] [PubMed]

6. Hwang, K.S.; Lee, M.H.; Lee, J.; Yeo, W.-S.; Lee, J.H.; Kim, K.-M.; Kang, J.Y.; Kim, T.S. Peptide receptor-based selective dinitrotoluene detection using a microcantilever sensor. Biosens. Bioelectron. 2011, 30, 249-254. [CrossRef] [PubMed]

7. Lafleur, J.P.; Jönsson, A.; Senkbeil, S.; Kutter, J.P. Recent advances in lab-on-a-chip for biosensing applications. Biosens. Bioelectron. 2016, 76, 213-233. [CrossRef] [PubMed]

8. Li, H.; Bai, X.; Wang, N.; Chen, X.; Li, J.; Zhang, Z.; Tang, J. Aptamer-based microcantilever biosensor for ultrasensitive detection of tumor marker nucleolin. Talanta 2016, 146, 727-731. [CrossRef] [PubMed]

9. Hwang, K.S.; Lee, S.-M.; Kim, S.K.; Lee, J.H.; Kim, T.S. Micro- and Nanocantilever Devices and Systems for Biomolecule Detection. Annu. Rev. Anal. Chem. 2009, 2, 77-98. [CrossRef] [PubMed]

10. Johnson, B.N.; Mutharasan, R. Biosensing using dynamic-mode cantilever sensors: A review. Biosens. Bioelectron. 2012, 32, 1-18. [CrossRef] [PubMed]

11. Ziegler, C. Cantilever-based biosensors. Anal. Bioanal. Chem. 2004, 379, 1-14. [CrossRef] [PubMed]

12. Burg, T.P.; Godin, M.; Knudsen, S.M.; Shen, W.; Carlson, G.; Foster, J.S.; Babcock, K.; Manalis, S.R. Weighing of biomolecules, single cells and single nanoparticles in fluid. Nature 2007, 446, 1066-1069. [CrossRef] [PubMed]

13. Sharma, H.; Lakshmanan, R.S.; Johnson, B.N.; Mutharasan, R. Piezoelectric cantilever sensors with asymmetric anchor exhibit picogram sensitivity in liquids. Sens. Actuators B 2011, 153, 64-70. [CrossRef]

14. Yoo, Y.K.; Chae, M.-S.; Kang, J.Y.; Kim, T.S.; Hwang, K.S.; Lee, J.H. Multifunctionalized Cantilever Systems for Electronic Nose Applications. Anal. Chem. 2012, 84, 8240-8245. [CrossRef] [PubMed]

15. Chae, M.-S.; Kim, J.; Yoo, Y.K.; Kang, J.Y.; Lee, J.H.; Hwang, K.S. A Micro-Preconcentrator Combined Olfactory Sensing System with a Micromechanical Cantilever Sensor for Detecting 2,4-Dinitrotoluene Gas Vapor. Sensors 2015, 15, 18167-18177. [CrossRef] [PubMed]

16. McLean, D.; Cooke, M.J.; Wang, Y.; Fraser, P.; George-Hyslop, P.S.; Shoichet, M.S. Targeting the amyloid- $\beta$ antibody in the brain tissue of a mouse model of Alzheimer's disease. J. Control. Release 2012, 159, 302-308. [CrossRef] [PubMed]

17. Smith, J.F.; Knowles, T.P.J.; Dobson, C.M.; MacPhee, C.E.; Welland, M.E. Characterization of the nanoscale properties of individual amyloid fibrils. Proc. Natl. Acad. Sci. USA 2006, 103, 15806-15811. [CrossRef] [PubMed]

18. Parbhu, A.; Lin, H.; Thimm, J.; Lal, R. Imaging real-time aggregation of amyloid beta protein (1-42) by atomic force microscopy. Peptides 2002, 23, 1265-1270. [CrossRef]

19. Cannon, M.J.; Williams, A.D.; Wetzel, R.; Myszka, D.G. Kinetic analysis of beta-amyloid fibril elongation. Anal. Biochem. 2004, 328, 67-75. [CrossRef] [PubMed]

20. Ogi, H.; Fukunishi, Y.; Yanagida, T.; Yagi, H. Seed-dependent deposition behavior of A $\beta$ peptides studied with wireless quartz-crystal-microbalance biosensor. Anal. Chem. 2011, 83, 4982-4988. [CrossRef] [PubMed]

21. Park, J.; Nishida, S.; Lambert, P.; Kawakatsu, H.; Fujita, H. High-resolution cantilever biosensor resonating at air-liquid in a microchannel. Lab Chip 2011, 11, 4187. [CrossRef] [PubMed]

22. Lue, L.F.; Kuo, Y.M.; Roher, A.E.; Brachova, L.; Shen, Y.; Sue, L.; Beach, T.; Kurth, J.H.; Rydel, R.E.; Rogers, J. Soluble amyloid beta peptide concentration as a predictor of synaptic change in Alzheimer's disease. Am. J. Pathol. 1999, 155, 853-862. [CrossRef] 
23. Vanderstichele, H.; Figurski, M.; Coart, E.; Siemers, E.; Lee, V.M.-Y.; Alzheimer's Disease Neuroimaging Initiative. Qualification of the analytical and clinical performance of CSF biomarker analyses in ADNI. Acta Neuropathol. 2011, 121, 597-609.

24. Cho, S.M.; Kim, H.V.; Lee, S.; Kim, H.Y.; Kim, W.; Kim, T.S.; Kim, D.J.; Kim, Y. Correlations of amyloid- $\beta$ concentrations between CSF and plasma in acute Alzheimer mouse model. Sci. Rep. 2014, 4, 6777. [CrossRef] [PubMed]

25. Lewczuk, P.; Matzen, A.; Blennow, K.; Parnetti, L.; Molinuevo, J.L.; Eusebi, P.; Kornhuber, J.; Morris, J.C.; Fagan, A.M. Cerebrospinal Fluid A $\beta 42 / 40$ Corresponds Better than A $\beta 42$ to Amyloid PET in Alzheimer's Disease. J. Alzheimers Dis. 2016, 55, 813-822. [CrossRef] [PubMed]

26. Langmuir, I. The adsorption of gases on plane surfaces of glass, mica and platinum. J. Am. Chem. Soc. 1918, 40,1361-1403. [CrossRef]

27. Crisostomo, A.C.; Dang, L.; Digambaranath, J.L.; Klaver, A.C.; Loeffler, D.A.; Payne, J.J.; Smith, L.M.; Yokom, A.L.; Finke, J.M. Kinetic analysis of IgG antibodies to beta-amyloid oligomers with surface plasmon resonance. Anal. Biochem. 2015, 481, 43-54. [CrossRef] [PubMed]

28. Schmidt, M.; Sachse, C.; Richter, W.; Xu, C.; Fändrich, M.; Grigorieff, N. Comparison of Alzheimer A $\beta(1-40)$ and A $\beta(1-42)$ amyloid fibrils reveals similar protofilament structures. Proc. Natl. Acad. Sci. USA 2009, 106, 19813-19818. [CrossRef] [PubMed]

29. Chiti, F.; Dobson, C.M. Protein Misfolding, Functional Amyloid, and Human Disease. Annu. Rev. Biochem. 2006, 75, 333-366. [CrossRef] [PubMed]

30. Ryu, J.; Joung, H.-A.; Kim, M.-G.; Park, C.B. Surface plasmon resonance analysis of Alzheimer's beta-amyloid aggregation on a solid surface: From monomers to fully-grown fibrils. Anal. Chem. 2008, 80, 2400-2407. [CrossRef] [PubMed]

31. Palladino, P.; Aura, A.M.; Spoto, G. Surface plasmon resonance for the label-free detection of Alzheimer's $\beta$-amyloid peptide aggregation. Anal. Bioanal. Chem. 2015, 408, 849-854. [CrossRef] [PubMed]

32. Johnson, B.N.; Mutharasan, R. Sample Preparation-Free, Real-Time Detection of microRNA in Human Serum Using Piezoelectric Cantilever Biosensors at Attomole Level. Anal. Chem. 2012, 84, 10426-10436. [CrossRef] [PubMed]

33. Johnson, B.N.; Mutharasan, R. A Cantilever Biosensor-Based Assay for Toxin-Producing Cyanobacteria Microcystis aeruginosausing 16S rRNA. Environ. Sci. Technol. 2013, 47, 12333-12341. [CrossRef] [PubMed]

34. Knowles, T.P.J.; Shu, W.; Huber, F.; Lang, H.-P.; Gerber, C.; Dobson, C.M.; Welland, M.E. Label-free detection of amyloid growth with microcantilever sensors. Nanotechnology 2008, 19, 384007. [CrossRef] [PubMed]

35. Lomakin, A.; Chung, D.S.; Benedek, G.B.; Kirschner, D.A.; Teplow, D.B. On the nucleation and growth of amyloid beta-protein fibrils: Detection of nuclei and quantitation of rate constants. Proc. Natl. Acad. Sci. USA 1996, 93, 1125-1129. [CrossRef] [PubMed]

36. Kotarek, J.A.; Johnson, K.C.; Moss, M.A. Quartz crystal microbalance analysis of growth kinetics for aggregation intermediates of the amyloid- $\beta$ protein. Anal. Biochem. 2008, 378, 15-24. [CrossRef] [PubMed]

37. Ramakrishnan, M.; Kandimalla, K.K.; Wengenack, T.M.; Howell, K.G.; Poduslo, J.F. Surface Plasmon Resonance Binding Kinetics of Alzheimer's Disease Amyloid $\beta$ Peptide-Capturing and Plaque-Binding Monoclonal Antibodies. Biochemistry 2009, 48, 10405-10415. [CrossRef] [PubMed]

(C) 2017 by the authors. Licensee MDPI, Basel, Switzerland. This article is an open access article distributed under the terms and conditions of the Creative Commons Attribution (CC BY) license (http://creativecommons.org/licenses/by/4.0/). 